"Disasta: Rethinking the Notion of Disaster in the Wake of Cyclone Pam", Anthropological forum, double special issue, 18 pages. Accepted.

Maëlle Calandra

Postdoctoral fellow at EPHE

Labex Corail-PSL /CREDO (UMR 7308 AMU-CNRS-EHESS)

Centre de Recherche et de Documentation sur l'Océanie

Aix-Marseille-Université

3, Place Victor Hugo

CS 80249

13331 Marseille Cedex 03

Tel: +33(0)4 13550732

Email: maelle.calandra@gmail.com 


\title{
Disasta: Rethinking the Notion of Disaster in the Wake of Cyclone Pam
}

\begin{abstract}
Tongoa was one of the worst-hit islands in Vanuatu when it was struck on 13 March 2015 by Cyclone Pam, the most severe climatic event recorded in the South Pacific for several decades. Nearly all of the buildings on Tongoa were damaged by winds and flooding.. However exceptional this cyclone might have been, such disruptive events are frequent and widespread on Tongoa Island: landslides, volcanic eruptions, cyclones and droughts all contribute to shaping the universe of its inhabitants. This paper seeks to understand the category of disasta or 'disaster' and how it is constituted in the context of Tongoa Island, where there is no vernacular word to express the concept of catastrophe. Disasta is a subjective Bislama term, varying with circumstances, the impact of the phenomenon and the cultural and social identity of the group affected. Is there a threshold with which to measure and define disasters? Reflections from the perspective of an anthropology of nature and an anthropology of disaster reveal how considerations around the notion of catastrophe are closely intertwined with the relationships between people and their environment.
\end{abstract}

Key words: Disaster, Cyclone Pam, Vanuatu, Tongoa, nature. 


\section{Introduction}

Figure 1 : The major islands of Vanuatu

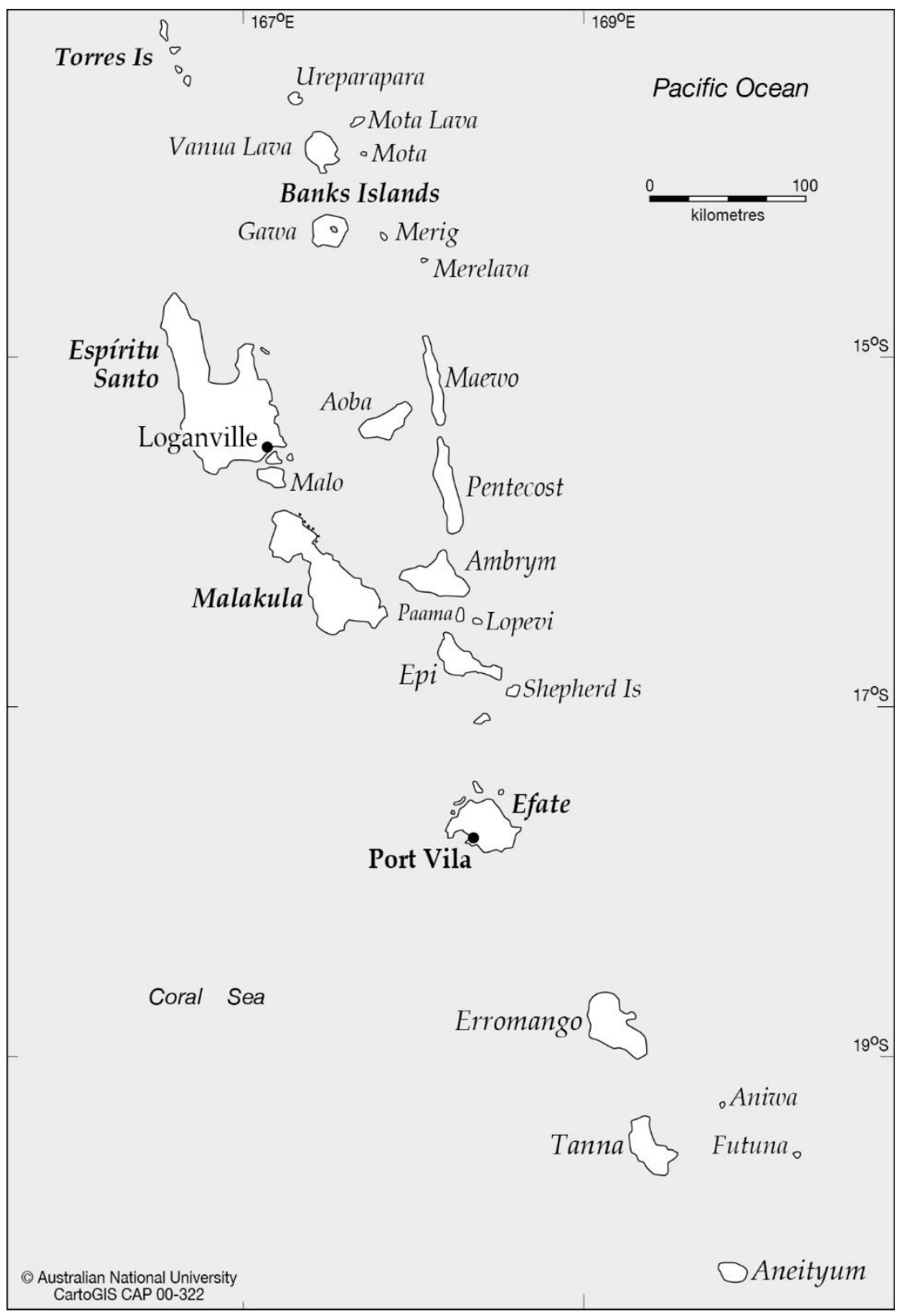

Tropical Cyclone Pam, a category 5 event, was the most severe climatic event recorded in the South Pacific for several decades. With winds gusting at over $350 \mathrm{~km}$ it devastated much of the Vanuatu archipelago, located in the South Pacific, from 12-14 March 2015 (Leone et al. 2015). Tongoa was one of the worst-hit islands of the archipelago . Torrential rains, rough seas and high winds devastated the landscape and livelihoods; the shore was covered with a thick layer of eroded soil, the vegetation was stripped of its leaves, the subsistence gardens were wrecked, and most houses were damaged. However exceptional this cyclone might have 
been at a national scale, such disruptive episodes are frequent and widespread on Tongoa: landslides, volcanic eruptions, cyclones and droughts all contribute to shaping the universe of its inhabitants.

The anthropology of disasters focuses on understanding how physical phenomena become catastrophic events. As such, it builds upon the anthropology of risk and its cultural theory of risk (Douglas \& Wildavsky 1982; Beck 1986), as well as on disaster studies which focus on environmental vulnerability (Wisner et al. 1977). Drawing from a more 'radical' approach, in which disaster is considered itself the main object of research (Hoffman \& Oliver-Smith, 2002; Revet, 2007; Langumier, 2008; Revet and Langumier, 2013; Moreau, 2017). This paper seeks to understand the category of 'disaster' and how it is constituted in the context of Tongoa Island, where there is no vernacular word to express the concept of catastrophe but only the Bislama (Pidgin) term disasta. In this ethnographic study, my aim is to show that disasta is a subjective and cultural term, varying with circumstances and the impact of the phenomenon. What I propose is that this notion encompasses a wider reality than the current framing of disasters in the literature suggests. I briefly review the historical and semantic development of the meaning and uses of the notion of catastrophe. Then, I analyse what can be called a 'disaster' and what the notion of disasta means to Tongoan people. In order to highlight how considerations concerning the notion of catastrophe are closely intertwined with relationships between people and their environment, I consider Tongoan categories of disaster in order to propose a vernacular grammar of disasta. I will not attempt to reconstruct the semantic history of imported words in Bislama. Instead, I analyse how the uses of contemporary words such as 'disaster' or 'natural' are integrated within local typologies. Finally, I explore the ways in which events that might usually be understood as disasters are configured in local narrative and exegesis. While many anthropologists ask how disaster, construed as a foreign and external object, collides with culture, my research asks how massive disruptions are understood within local systems of meaning and materiality.

\section{Catastrophe as a Category of Thinking}

\section{The Genesis of the Term}

In order to understand the construction of meaning for the word 'catastrophe' in Western societies, I briefly outline its history and semantics. Etymologically, the term 'catastrophe' is 
derived from the Latin catastropha, literally 'to reverse' and the Greek katastrophê 'overturning'. The Greek root strophe comes from the verb sterphein (the action of turning, twisting, to overturn) and from the prefix kata which means downwards, expressing the idea of completing the action (Quenet 2000,17). Thus, the term katastrophê evokes the inexorable reversal of a condition.

In ancient Greece, katastrophê referred to a simple observation, similar to that of a spectator (Moreau 2017,19) and was also associated with dramatic art. It expressed the denouement of a tragedy drama with the feeling of catharsis experienced by the audience. The term katastrophê was thus ambivalent, as tragedies could either end well or badly. Western constructions of the analytical category of catastrophe have largely retained this idea of a sudden and ill-fated reversal of the situation, associated with the characteristics of the final moments of ancient Greek plays.

It was not until the 18th century that the word 'catastrophe' left the literary context to become part of the scientific domain. In the course of this century, the word gradually took on its modern meaning, evoking chaos and destruction. The naturalisation and laicisation of natural phenomena associated with the Enlightenment are commonly held to have been initiated by the 1755 Lisbon earthquake (Paice 2008). Publications following the event encouraged the elaboration of the catastrophe paradigm and allowed its meaning to be generalised. By the end of the 18th century, the word 'catastrophe' was in widespread use and referred to a disastrous, exceptional and brutal event that interrupts 'the course of the physical order of things' (Bethemont 1991, 139), delimiting a before and an after (Quenet 2010, 22).

Nowadays, dictionaries unanimously define a disaster as an exceptional event which creates large-scale damage. For example, The Oxford English Dictionary describes a disaster as a 'sudden accident or a natural catastrophe that causes great damage or loss of life' (Stevenson 2010). According to Yves Gauthier (n.d.), the author of the entry 'catastrophe' in the Encyclopadia Universalis, 'disasters are events producing serious consequences for life in general, human beings in particular, environment, and infrastructure'.

Throughout its long history of usage, 'catastrophe' has retained a deep link with drama and harm. We now speak about 'catastrophe scenarios', a form also pursued by the film industry with 'disaster movies' which attract an ever-growing audience. According to Christian Godin 
$(2009,6)$, these visual productions have a function of 'deliverance and of prophylaxis', echoing the concept of catharsis developed by Aristotle. This treatment of large-scale events across multiple media also reveals the presumed link between catastrophe and audience.

The Greek theatrical origin of the word 'catastrophe' has also given rise to reflections on what Yoann Moreau $(2017,21)$ calls 'a grammar of the spectacular'; he suggests that nowadays, to be considered a disaster, an event must respect the grammatical structure of the rule of the three unities (time, space, and action). It must be limited in time, sudden and rare; it must take place in a delimited area and its consequences must be measurable and quantifiable. Nevertheless, disasters are, also, human creations: they are both mediated by the effects of human agency and produced by humans as a category of events, requiring a specific explanation and response as they are not constructed ex nihilo (Clavandier 2015, 99). And yet, the variability in the scope, scale and the frequency of natural disasters impart an exceptional degree of uncertainty to their interpretation. Not all societies are 'catastrophists': the ethnographic case of Tongoa demonstrates that disasters do not always need to be conceived as harmful events.

\section{Disasta: an Intermediate Notion}

Tongoa is a small island $\left(42 \mathrm{~km}^{2}\right)$ located in the Shepherd Islands group of central Vanuatu, where nearly 2,300 people live in 14 different villages (see Figure 1 and 2) and speak either or both of two languages, Namakura or Nakanamanga. One of the particular features of this island is its location near the submarine volcano Tompuku (called Karua by the scientific community). According to oral tradition, Tompuku is a nickname given to Pae, a mythical being held responsible for a very large volcanic eruption, which he is said to have caused to punish his fellow villagers (Calandra 2013). Indeed, people explain that the fire came out of the mouth of a green lizard that was used by Pae to generate the eruption. Radiocarbon results suggest that this volcano apparently erupted in $1452 \mathrm{AD}$ (Gao et al. 2006, 1), and it is widely recognised as one of the three largest volcanic events in the world over the past 2000 years (Wang et al. 2012, Zanchettin et al. 2012). Contemporary Tongoan society was literally born from the cataclysm of the Kuwae eruption, and Tongoan lives are still lived in the eternal shadow of this event, which has left its indelible marks on the landscape. Nowadays, 
Tompuku is still active - it is said that the lizard is still alive in its bosom -, generating small submarine eruptions that occasionally create ephemeral islands (see Figure 2).

Figure 2: Map of Tongoa island

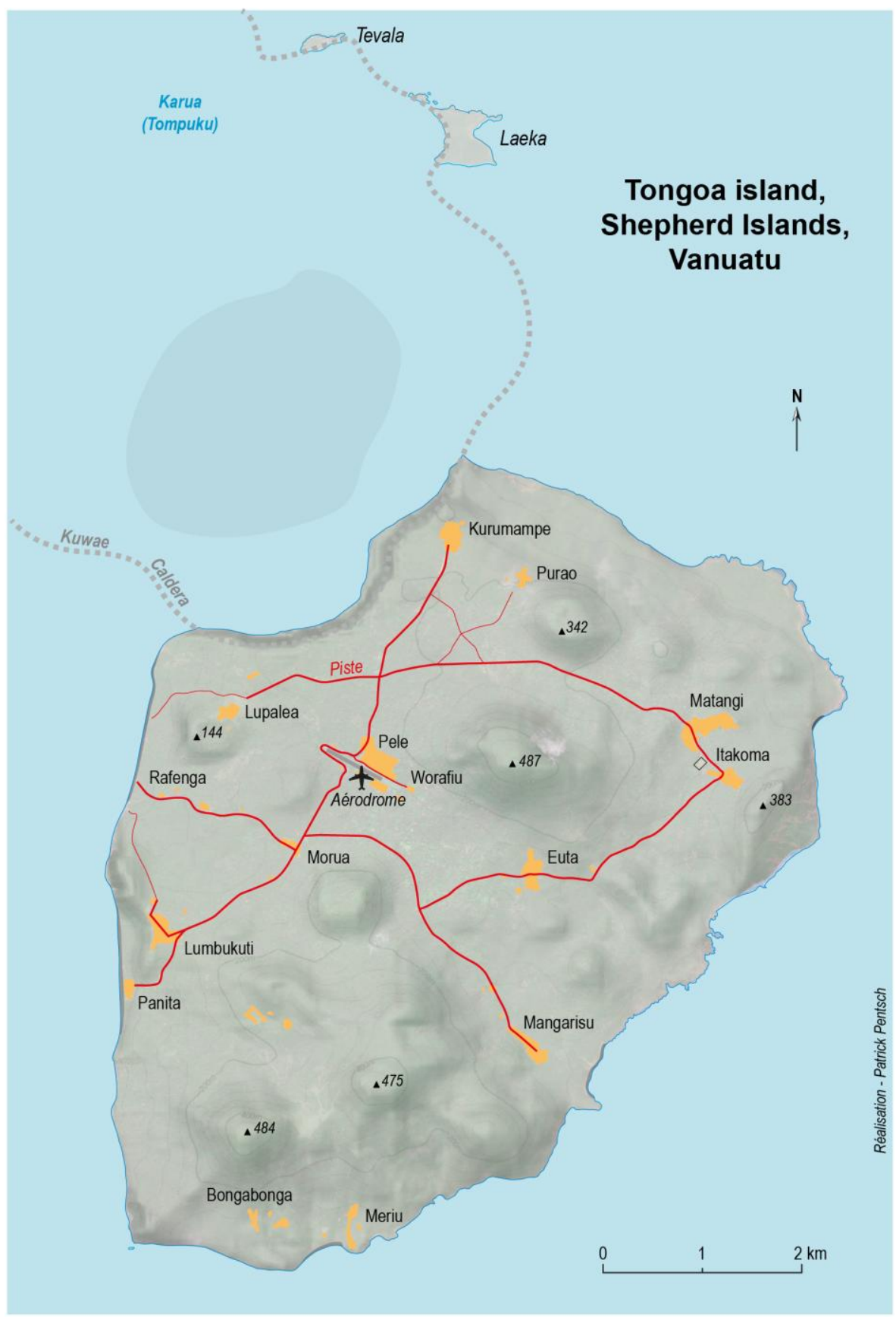

Besides volcanic risks, the island of Tongoa is also exposed to other types of disruptive events, such as cyclones, landslides, earthquakes, droughts, etcetera. Interestingly, there is however, no word in the vernacular languages that corresponds strictly to the notion of catastrophe. This does not mean that a disruptive episode with lasting consequences cannot be 
considered what is understood by catastrophe nowadays. To speak of such an event, Tongoans use the Bislama term disasta, a word derived from the English 'disaster', the introduction of which is recent, since it was not present in local speech before the mid $2000 \mathrm{~s}^{1}$. Disasta is commonly used by Tongoans to describe a variety of noteworthy events of various origins (human and non-human), which have a negative impact on the environment and can threaten human existence or cause irreversible loss (material, symbolic, human and non-human). Throughout my different periods of fieldwork in the village of Kurumampe (north Tongoa) between 2011 and 2018, I observed the ways in which disasters are configured in local narratives and exegesis. I wanted to understand if there was a threshold which Tongoans used to measure and define disasters. To this end, I listed the various situations that the inhabitants referred to as disasta, particularly during informal discussions or weekly meetings at the farea (the village's communal house), where people discussed and negotiated incidents (such as the theft of tubers, disputes between families, forays by animals into subsistence gardens, accusations of witchcraft, etc.) that had happened during the week. It is the amplitude of loss that allows a family to describe an event as a disasta, and the assessment of a disasta sometimes gives rise to tears because of its lasting effects.

The analysis of these village discussions show that it is the extent of the damage caused to food or cash crops and its expected consequences which leads to an event being qualified as a disasta. For example, in November 2013, Tapao and his wife Nagege from Kurumampe village complained about the repeated incursions of animals into their watermelon garden, as they wanted to sell the fruit to pay their eldest son's school fees ${ }^{2}$. The beasts had got into the plot, eaten the fruits and trampled the plants. Designated as a disasta by Tapau and his wife, this event was discussed at the farea by the assembled community. The cows were designated responsible for the damage and the assembled community undertook to assess the amount of compensation that the cows' owner would have to pay to the wronged couple. When the yam seedlings of Tata Samoa, an older Tongoan woman of Kurumampe village, were stolen in October 2014, she declared that a disasta had happened, as she would not have any tubers to offer Taripoamata (the village chief) for the yam ceremony which takes place every year in April. In November 2014, after several days of heavy rains, Royline Roy claimed that a disasta had happened in her yam garden, because the excess rainfall had made the yam vines

\footnotetext{
${ }^{1}$ In the second edition of Crowley's 2003 Bislama dictionary, the words "disasta" or "disaster" do not figure

${ }^{2}$ On Tongoa the majority of the population doesn't have a salary. The main income is provided by selling their plant or animal products at the market of the island or in the capital Port-Vila.
} 
yellow and the tubers had started to rot. These three events illustrate that a catastrophe may or may not have a known cause, and may or may not involve compensation, but in all cases reflects a character of loss or expected loss. However, the category of disasta does not rely on these criteria alone.

On Tongoa, a disasta is evaluated largely on the basis of the state of gardens, rather than in terms of the material damage caused to buildings and other property, as is the case in the Western world. The study of the different events qualified as disasta by Tongoan inhabitants reveals that the subsistence garden is the principal frame of reference. It is when crops are wiped out by a sudden event (cyclone, earthquake, drought, theft, animal incursions, sickness, parasites, etc.) that the situation is commonly described as a disasta. The condition of subsistence gardens provides the threshold for measuring the significance and describing the nature of a disasta. The situation is considered even more catastrophic when a disruptive event happens between two harvests or when it occurs several times during the same season. If the garden provides for the daily nutritional needs of the family, the disasta endangers selfsufficiency, as it takes months, if not years, for the plant regime to be reconstituted. Moreover, crops are sometimes irreversibly lost. For example, Cyclone Pam led to the total loss of three of the eighteen cultivars of manioc identified in 2013 (Calandra 2017, 294).

Therefore, a cyclone that has not completely destroyed the gardens is not described as a disasta, as we shall see later. This singles out a remarkable aspect of what can be considered a disasta in the context of Tongoa Island. When Cyclone Atu struck on the night of 20 February 2011, most of the local kitchens in the village of Kurumampe were damaged and the majority of ripe fruit fell from the trees in the gardens - bananas, grapefruits, oranges and avocados -, yet very few people qualified this event as being a disasta. For, even though some houses were partially destroyed, the gardens were not substantially affected by the storm: sweet potatoes, yams, and taros had been spared by the cyclone. Only a few manioc plants and banana trees suffered damages, but not in sufficient quantities to jeopardise the community's food security.

It thus appears that it is the nature of the damage caused that is the key denominator of what is or is not deemed a disasta. As I will now highlight considering a series of binary oppositions, a disaster does not always fit into a 'natural' axiology on Tongoa Island. Although disasta seems to encompass events that could be synonymous with the Western concept of disasters, Tongoans distinguish between different forms of disasta according to their contingencies. 


\section{The Attributes of Disasta}

\section{Predictable and Unpredictable Forms of Disasta}

Although on Tongoa the disasta seems to be 'an irrefutable fact' because of its recurrence, Tongoan discourse makes a distinction between different forms of disasta depending on the circumstances of their occurrence. The analysis of the diverse situations qualified as disasta by Tongoan people reveals that factors surrounding their occurrence are a significant characteristic of what a disaster is in this specific context. The occurrence factor is a significant characteristic of what constitutes a disaster in a given context.

In Tongoan representations, a disasta can be foreseeable, which means that certain indicators present in the environment signal the potential occurrence of a dangerous and devastating event. For example, Tongoans know that cyclones happen mainly during the hot season; they notice that trees are overloaded with more fruit than usual and that, just before cyclones arrive, the sky turns red, mala birds (Fregata minor) fly higher, and the weather is hotter than usual, etc. Tongoans also know the indicators of a potential resumption of activity from the nearby submarine volcano: the colour of the sea's surface turns yellow and, just before the eruption, it becomes red. The smell from the fumaroles below the village of Kurumampe is also stronger than usual and the hydrogen bubbles emanating from the caldera are much bigger. These hazards can be foreseen because they have a certain seasonality or a kind of cyclical regularity and happen not suddenly but gradually. They provide the population the opportunity to prepare for them by taking preventive measures: cutting down banana trees and manioc plants before a cyclone, or hiding in a Pele village ${ }^{3}$ to escape a volcanic eruption.

At the other end of the scale, there is the unpredictable disasta which can take place at any time. There are no 'warning indicators' in the environment, thus it always takes its victims by surprise. These kinds of disasta are particularly dreaded as, although they are rare, people know that they will recur sooner or later and always inflict major damage. This is notably the case for earthquakes, which Tongoans say they cannot anticipate, or that of animal' incursions into the gardens. As Tata Samoa said of the latter: 'When animals come into your garden, when they eat everything, it is a disasta which has no season!' This sort of disasta also

\footnotetext{
${ }^{3}$ Pele is the furthest village from the submarine volcano. It is located in the center of the Island (see figure 2).
} 
includes the stealing of locally-valued tubers, such as yams or kava. In local people's representations, all these events are considered unpredictable, massive and sudden. In addition to this important distinction between types of disasta based on its predictability, inhabitants make a further distinction regarding its origin and causes: a disasta can be either natural or 'man-made'.

\section{A Distinction in Nature: 'Man-Made' vs 'Natural' Disasta}

Disruptive events on Tongoa are distinguished according to their causes. The local population identifies two broad classes of events: one is the result of human action, or 'made' (meriana), whereas the other is classified as being 'natural' (najurol). A cyclone is considered 'manmade' (nalangni meriana) ${ }^{4}$ when, for example, it occurs outside the cyclone season, is more violent than usual, or happens several times during the same period. In 2011, Cyclone Atu was considered to have been made by a man from Pentecost (the tropical storm had evolved into a hurricane near the island of Pentecost and then moved from north to south). Tapao, a villager of Kurumampe, said: 'Atu was made by a man-Pentecost who lost control of it, that's why it came to hit us'. The inhabitants provided the same interpretation of Cyclone Pam. Because it caused major damage, it was thought of as the act of a man who was jealous of another person's gardens. This cyclone was also interpreted in a different way: as a creation of God, a divine punishment for human misbehaviour. In this perspective, though God creates the catastrophe, the ultimate responsibility for it lies with humans (Calandra, 2017). Other events can also be considered to be 'man-made' disasta: animal forays into fields, sudden floods or long droughts. All these events, because they are considered to not follow the normal course of things, are considered as being 'made' by someone.

What all of these different examples of disasta have in common is that they are the result of an act of human will or the consequence of human action. Furthermore, the advent of a manmade disasta is linked to particular events that occur both in the human community (land dispute courts, weddings, kastom ceremonies, funerals, etc.) and in the gardens (planting, harvesting). Finally, this type of disasta is also characterised by the indeterminacy concerning its progress (as embodied in the change in trajectory of a cyclone, rain falling at unexpected times, drought continuing beyond the dry season, pigs repeatedly devastating the same

\footnotetext{
${ }^{4}$ Literally « the made wind ».
} 
garden, and so on). Thus, disasta has an eminently contextual and subjective dimension, as it depends on both the observers and the context.

When the occurrence of a life-threatening event seems to be beyond human control in the sense that no one can be identified as being responsible for it, or when the event is thought to be part of 'normal' and expected life in the long term, it is described as a 'natural' disasta. A phenomenon is interpreted as 'najurol' (natural) in Bislama when its occurrence is independent of any human will and when no one seems to have intervened to make it happen. For example, although devastating, a cyclone can be considered intrinsically linked to the cycle of seasons. An earthquake can also be thought of in these terms: its occurrence is justified by the theory of plate tectonics, which is now taught at primary school. A re-eruption of the Tompuku volcano is related to the presence of the legendary lizard still alive and present in its bosom (see Figure 3). According to the Tongoan interpretation, this type of disasta is also considered natural because here again no human has intervened to generate it: it is the lizard who is responsible for the eruption (Calandra 2013). This category of najurol disasta is therefore defined in opposition to the 'made disasta'. However, despite the influence of exogenous notions and the perception of risks introduced by NGOs and government agencies, 'natural' explanations for the occurrence of disasta remain less common (see also Ballard et al, this issue). We may thus surmise that the vocabulary and semantics that relate to disasta in general terms have to some extent been westernised through the influence of Bislama and NGOs, which are increasingly involved in the domain of disaster risk reduction in Vanuatu. Indeed, we may assume that the rather new category 'najurol disasta' now also integrates those events that were formerly attributed to non-human causes (which is the still the case for the volcanic eruption caused by the lizard). Today, the word naturol as used by the Tongoans to characterise an event, embodies an extension of the former traditional and mythological understanding of such events. Every disasta has a circumstantial dimension and similar events can be perceived quite differently. Indeed, the same type of catastrophe can be thought as being either najurol or man-made, depending on the context, the observer, as well as the moment or period during which it occurs. We now turn to consider how Tongoan understandings the appreciation of disasta can evolve over time. 
Figure 3: The green lizard into the volcano's bosom. Drawn by Nakarame, man of 70 years old, 21/02/11, Kurumampe.

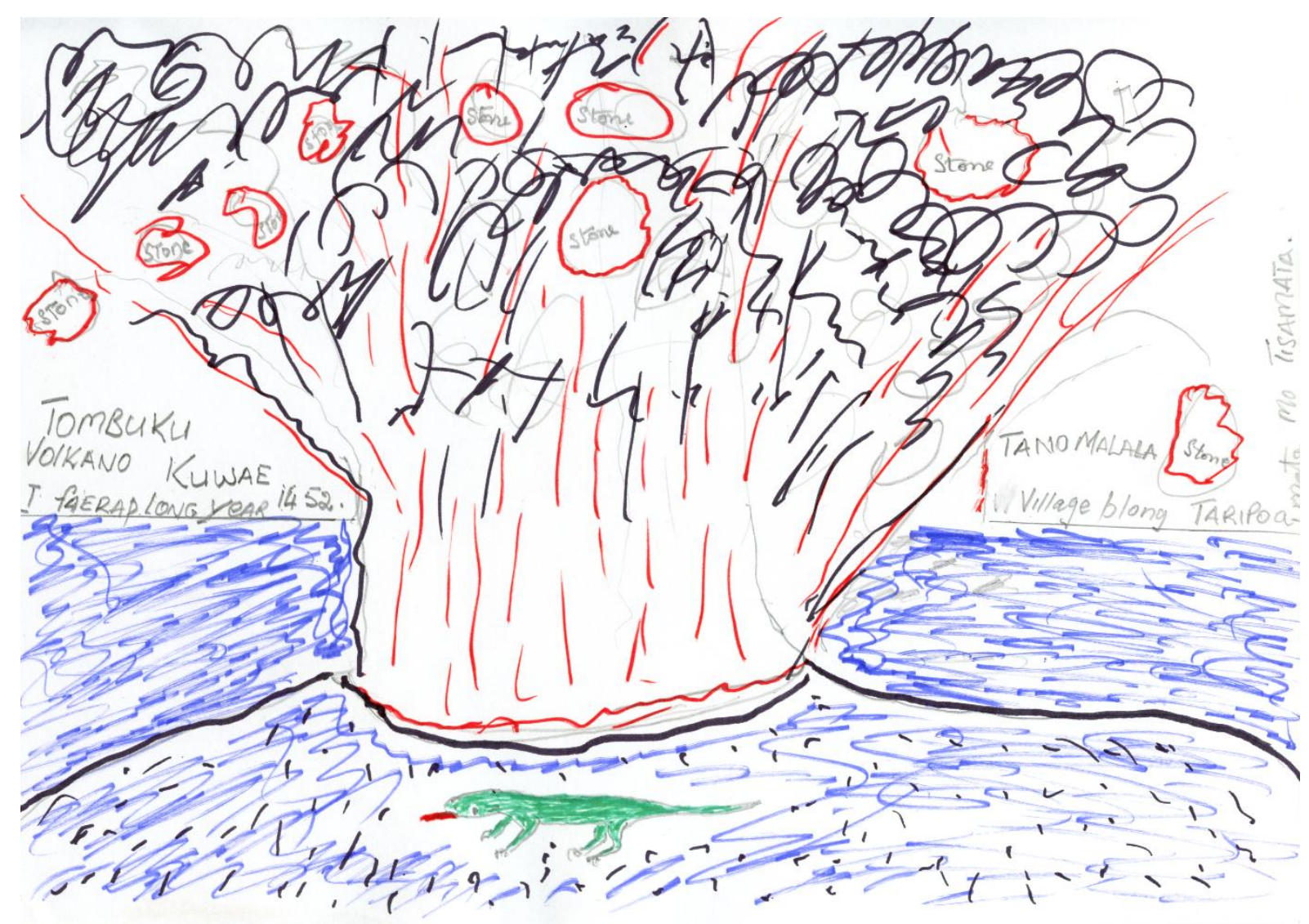

\section{The Axiology of Disasta}

Positive and Negative Forms of Disasta

On Tongoa, a scale is used to rank different disasta events depending on the marks on the environment that each episode leaves in its wake. It can be characterised in the local vernacular as e piya (good, nice), or nasaana (bad), bearing either positive or negative connotations. When Tongoans consider that a cyclone has occurred at the right time in relation to the growth cycle of tubers, it is qualified in Bislama as gud nius 'good news'. Moreover, a disasta is considered positive if people know that it will be beneficial to their environment, within a certain time frame. As Tata Samoa explained: 'After a cyclone, we all know that plants will regrow better, that's why sometimes cyclones occur for the sake of the community'; if plants are not healthy or in sufficient quantities, the various ceremonies will not happen during the year. Occasionally the village chief may ask a wind-maker to create a 
cyclone for the sake of the community. After Cyclone Atu, despite the damaged houses in the villages, the inhabitants considered this event to be 'good news'. It occurred when the yams were almost ready and did not affect their growth, while the fallen fruit (mainly grapefruit and oranges) was sold to people on the capital island of Efate. The seawater mixed with rainfall had fertilised the soil and eradicated parasites and diseases, and the water tanks were full of fresh water (cyclone water is highly-valued locally). Moreover, a few weeks later, the inhabitants declared that they had noticed how the gusts of wind had stimulated the growth of trees. In July 2018, three years after Cyclone Pam, the most destructive cyclone since the 1980s, the inhabitants again declared the cyclone to have been a positive event in the long run, as today the gardens are more productive than ever before.

In contrast, certain disasta - labelled as nasaana (negative) - are considered by the Tongoans as having only harmful effects because they give rise to misfortune in the daily lives of those who are affected. From this perspective, Cyclone Pam was described as a 'made disasta' and was regarded negatively, because the high winds caused extensive damage, gardens were wiped out and the excessive salt from the sea water 'burned' (maso) the soil, making the growth of new plants difficult for many months. Moreover, the cash crops (the island's main economic resource) were ruined. In fact, Cyclone Pam jeopardised the livelihood of the entire community.

No Longer Disasta

On Tongoa, the evaluation of disasta effects may vary over time. A calamity can be evaluated initially by the inhabitants as being negative and later be credited with positive aspects. For example, in the case of the flow of volcanic ash from the Tompuku vent, the acidity of the ash was first harmful for plants, but with time it enriched the soil. In this sense, Tongoan people explained that, because of the numerous eruptions, their island is becoming particularly suitable for the culture of subsistence plants and cash crops.

Cyclone effects can also evolve with time. Villagers have noticed that the salt from the sea projected into their plots by gusts of wind gradually acts as a source of nutrients that benefit plant growth and development. People made the same observation after a minor earthquake, since this phenomenon could as well be described as a positive event for gardens. According to Tia Toara, an old man from Kurumampe village, because seismic events cause trees to shake from their roots to their very tops, they favour the rise of sap and therefore fruit 
production. Having analysed the consequences of disasta on the environment, I will now examine the ways in which disasta can also engender social decay and conflict.

\section{The Scale of Disasta}

In Tongoan discourse, I have noticed that a disasta is more often described as being negative when it concerns only a few people, such as when animals make incursions into gardens. For the concerned individuals, this kind of disasta is the worst, as it is always unforeseen. It is also considered unfair because not everyone is affected. Its consequences are dramatic because it ruins the crops and thus the livelihood of the family concerned. Furthermore, the sense of powerless to predict and prepare over the situation reinforces this negative interpretation of disasta. It should be noted that all these criteria reflect the 'dramaturgic grammar' discussed earlier in this paper. Not all disasta events produce the same social results. A large-scale disasta affecting the entire community - like a cyclone, earthquake or volcanic eruption - will create and reinforce social relationships between people because everyone is impacted. However, when a disasta affects only one family, the community feels less concerned and the members of that family are less likely to receive support from others, and more likely to identify the event negatively, as a disasta.

Finally, the notion of disasta is primarily related to the state of gardens. Whether or not people qualify an event as being a disasta depends on the damage caused to crops. This is why the state of subsistence gardens can be considered as the most significant frame of reference for disasta. The notion of disasta condenses several different characteristics : it can be foreseeable or not ; its origin can be najurol or "man made" and, according to its perceived intensity, the disasta can have small and local or general and widespread effects on the environment. In addition, it may be described as being either a positive or negative event and may (or may not) reinforce relationships between villagers.

\section{Conclusion}

Grasping the cross-cultural dimensions of disaster requires an appreciation of different theories of causality and moral economies of attribution. Discourses and narratives about disaster capture the moralising will to attribute the responsibility of disasters to particular agents and human attitudes: people, government, God, climate change, sorcery (nakaemas), jealousy, etcetera. 
Although the examples provided here suggest that representations of catastrophes on Tongoa are standardised, this is in fact not the case. Distinctions in ways of understanding and explaining disasta vary with age, religious affiliations, level of education and migration trajectory. Beyond highlighting the fact that the notion of disaster is fundamentally subjective, the different explanations provided to explain catastrophes are a glimpse of how people on Tongoa think of their environment. 'Nature' is rarely held responsible for the disasters that occur and the laws of nature are hardly ever invoked. On Tongoa, disasters are more commonly thought of as being intentional and related to human action rather than being the result of fate. Such considerations lead me to conclude that the specific ways of thinking about disruptive events make Tongoans less inclined to feel vulnerable when they are confronted with them. Finally, I have argued that the vernacular grammar of disasta covers a wider range of phenomena than those embraced by conventional Western definitions of catastrophe. The understanding and use of the Bislama term disasta has much to offer to current debates around the relationship between culture and disaster in allowing us to refer to major events, while avoiding the pitfalls of catastrophe or the spectacular.

\section{Acknowledgements}

I wish to acknowledge the helpful advice provided by my two $\mathrm{PhD}$ supervisors Philippe Descola and Pierre Lemonnier. I am grateful to Chris Ballard, Yoann Moreau and Borut Telban for their suggestions for improvements. I also wish to thank the journal's anonymous reviewers and editors for their feedback on previous versions of this paper.

\section{Notes}

${ }^{1}$ In the second edition of Crowley's 2003 Bislama dictionary, the words "disasta" or "disaster" do not figure.

${ }^{2}$ On Tongoa the majority of the population doesn't have a salary. The main income is provided by selling their plant or animal products at the market of the island or in the capital Port-Vila.

${ }^{3}$ Pele is the furthest village from the submarine volcano. It is located in the center of the Island (see Figure 2).

${ }^{4}$ Literally "the made wind". 


\section{References}

Beck, U. 2001 [1986]. La Société du risque: Sur la voie d'une autre modernité. Paris: Flammarion, "Champs".

Bethemont, J. 1991. Sur la nature des événements extrêmes: catastrophe et cataclysme. Revue de géographie de Lyon 66 (3-4): 139-142.

Calandra, M. 2017. Jardins de terre, jardins de mer. Une anthropologie de la nature domestique dans un milieu affecté par la catastrophe. PhD diss. Paris: École des Hautes Études en Sciences Sociales.

2013. Faire dessiner le terrain. La nature à «risques » et les jardins de subsistance de Tanna et Tongoa (Vanuatu). Techniques \& Culture 60 (1): 182-201.

Clavandier, G. 2015. Un retour de la catastrophe sur la scène scientifique? Enjeux et débats. Communications 96 (1): 93-105.

Crowley, T. 2003. A New Bislama Dictionary. 2nd ed., Port Vila: Institute of Pacific Studies/ University of the South Pacific.

Douglas, M., et Wildavsky, A. 1982. Risk and Culture: An Essay on the Selection of Technical and Environmental Dangers, Berkeley: University of California Press. Gao, C., A. Robock, S. Self, J. Witter, J.-P. Steffenson, H. B. Clausen, M.-L. SiggaardAndersen, S. Johnsen, P.A. Mayewski and C. Ammann 2006. The 1452 or 1453 A.D. Kuwae eruption signal derived from multiple ice core records: Greatest volcanic sulfate event of the past 700 years. Journal of Geophysical Research 111 (D12107): $1-11$.

Gauthier, Y.n.d. Catastrophes. Encyclopadia Universalis. [Online]. Consulted 29 March 2018. http://www.universalis.fr/encyclopedie/catastrophes/.

Godin, C. 2009. Ouvertures à un concept: la catastrophe. Le Portique 22: 1-12. [Online]. Consulted 29 March 2018. http://leportique.revues.org/1993.

Hoffman, S., Oliver-Smith, A. (eds.). 2002. Catastrophe and Culture. The Anthropology of Disaster, Santa Fe/Oxford: School of American Research/James Currey.

Langumier, J. 2008. Survivre à l'inondation. Pour une ethnologie de la catastrophe, Paris : ENS Éditions.

Leone, F., Rey, T., Le De, L., David, G. 2015. Rapport de mission scientifique exploratoire post cyclone Pam au Vanuatu.

Moreau, Y. 2017. Vivre avec les catastrophes. Paris: Presses Universitaires de France/Humensis.

Paice, E. 2008. Wrath of God: the Great Lisbon Earthquake of 1755. London: Quercus 
Quenet, G. 2000. La catastrophe, un objet historique? Hypothèses 3 (1): 11-20.

Quenet, G. 2010. Fléaux de Dieu ou catastrophes naturelles? Les tremblements de terre en France à l'époque moderne. Terrain 54 (1): 10-25.

Revet, S. 2007. Anthropologie d'une catastrophe. Les coulées de boue de 1999 au Venezuela, Paris: Presses Sorbonne nouvelle.

Stevenson A. 2010. Oxford Dictionary of English. 3rd ed. New York, NY: Oxford University Press.

Wang, T., Ottera, O., Gao, Y., Wang, H. 2012. The response of the North Pacific Decadal Variability to strong tropical volcanic eruptions. Climate Dynamics 39 (12): 2917-2936.

Wisner, B., O’Keefe, Ph., Westgate, K. 1977. Global Systems and Local Disasters: The Untapped Power of Peoples' Science . Disasters 1 (1) : 47-57.

Zanchettin, D., Timmreck, C., Graf, H-F., Rubino, A., Lorenz, S-J., Rubino, A., Krüger, K., Jungclaus, J-H. 2012. Bi-decadal variability excited in the coupled ocean-atmosphere system by strong tropical volcanic eruptions. Climate Dynamics 39 (1-2): 1-26. 